ORIGINAL ARTICLE

\title{
Mortality and cancer incidence in New Zealand meat workers
}

\author{
D Mclean, S Cheng, A 't Mannetje, A Woodward, N Pearce
}

Occup Environ Med 2004;61:541-547. doi: 10.1136/oem.2003.010587

See end of article for authors' affiliations

....................

Correspondence to: Dr D McLean, Centre for Public Health Research, Research School of Public Health, Massey University Wellington Campus, PO Box 756 Wellington, New Zealand; D.J.McLean@ massey.ac.nz

Accepted 28 November 2003
Aims: To ascertain whether there is an increased risk of cancers of the lung and lymphohaematopoietic tissue in workers employed in the New Zealand meat processing industry, and to identify exposures associated with any increased risks.

Methods: A cohort of 6647 individuals assembled from personnel records from three plants was followed from 1988 until 2000. The observed number of deaths and cancer registrations was compared with expected numbers using five year age and gender specific rates for the New Zealand population. Subgroup analyses evaluated the effect of duration of exposure to selected agents, based on job titles and departments.

Results: Vital status was determined for $84 \%$ of the cohort, and $92 \%$ of the total possible person-years. Mortality from all causes and all cancers was increased, and there was a significant excess of lung cancer. There were significant trends of increasing risk of lung and lymphohaematopoietic cancer with increasing duration of exposure to biological material.

Conclusions: Excess risks were observed for mortality from all causes, all cancers, and lung cancer. Although the increased risk of lung cancer may be partly due to confounding by smoking, it is unlikely to be entirely due to this cause. Furthermore, the dose-response relation observed for lung cancer suggests the effect is related to exposure to biological material contained in animal urine, faeces, and blood. Although numbers were small, the risk of lymphohaematopoietic cancer was also associated with increasing duration and level of exposure to biological material.
A number of studies have suggested increased risks of cancers of the lung and larynx, and of leukaemia and lymphoma, among butchers and slaughterhouse workers. These findings have come from investigations conducted in several countries, over different time periods, and using a combination of study designs including analyses of routinely collected mortality and incidence data, ${ }^{1-5}$ of proportionate mortality and incidence, ${ }^{26-10}$ or case-control ${ }^{11-25}$ and cohort studies. $^{8-10}$ 26-31

Case-control studies have consistently shown increased risks for cancers of these sites among meat workers, with the highest risks associated with animal slaughter or contact with raw meat, ${ }^{19} 2324$ and with the findings for lung cancer persisting after adjustment for ${ }^{22}{ }^{23}$ or after using indirect methods to control for ${ }^{18}$ smoking. Although limited by study size $^{8-1026-28} 30$ or by relatively crude exposure assessment based on occupation listed at census, ${ }^{29}{ }^{31}$ the cohort studies conducted previously in Europe and the USA have found weaker associations than those found in case-control studies. They have shown relatively small increases in lung cancer relative risk, generally within the range that could be attributed to confounding by smoking, although higher risks have been observed among workers in abattoirs in contact with live animals or freshly slaughtered meat. ${ }^{102}$ These cohort studies have provided little evidence, however, of any increased risk of leukaemia or non-Hodgkin's lymphoma.

Potentially hazardous exposures in the meat industry are primarily biological, including bacterial and viral infectious agents as well as non-infectious bioaerosols, with most attention having been focused on animal retroviruses with known oncogenic potential. ${ }^{32}$ There is also a limited range of potential exposures from chemicals either used in the process or in the maintenance of plant and equipment, or encountered as residues of animal remedies or pesticides used on farms. There are also well recognised physical and psychosocial stresses $^{33}$ associated with work in this industry, including knife cuts, musculoskeletal injuries, machine pacing of work, and shiftwork.

Case-control studies conducted in New Zealand have shown consistently increased risks for cancers of the lymphohaematopoietic system ${ }^{13-16} 18$ and a clear doseresponse, ${ }^{24}$ although these have been based on relatively small numbers of exposed cases and relied on either routinely coded occupation or participants' recall of job titles and exposure. The meat processing industry is a significant employer in New Zealand, and in spite of the seasonal nature of the work, has a relatively stable workforce with annual turnover of only 10-15\%. However, no New Zealand cohort study of meat workers has previously been conducted. A National Cancer Registry with virtually complete registration, which was first established in 1948, also provides reliable cancer incidence data, ${ }^{34}$ and death registration data are also considered to be valid and virtually complete. ${ }^{35}$ This cohort study was therefore conducted to examine mortality and cancer incidence in New Zealand meat workers, to establish whether the findings of increased risks for cancers of the lymphohaematopoietic system in earlier case-control studies could be replicated, and also to examine the associations between specific exposures and any increased cancer risks.

\section{METHODS}

Three "freezing works" (meat processing plants) were included in this study. Plant A was located in the South Island, and operated six mutton chains and one beef chain. Copies of annual printouts of employee masterfiles, which

Abbreviations: SIR, standardised incidence ratio; SMR, standardised mortality ratio; NZHIS, New Zealand Health Information Service; WINZ, Department of Work and Income; PC LTAS, life table analysis system for use on the personal computer 
Main messages

- A significant excess of lung cancer was observed in this cohort of New Zealand meat workers processing sheep meat.

- While it is not possible to completely rule out the possibility of confounding by smoking and/or ethnicity, it is highly unlikely that either is sufficient to account for more than a small part of the excess observed.

- The strong dose-response relations observed add support to the hypothesis that the effect is related to occupational exposures, and in particular to some component of the biological material contained in animal urine, faeces, and blood (possibly oncogenic zoonotic viruses).

- Although numbers were small the study provided limited support for previous findings of excess risks of leukaemia and non-Hodgkin's lymphoma associated with work in the meat industry, due primarily to the association observed between risk and increasing duration and level of exposure to biological material.

contained full name and date of birth and listed job title and work area, were obtained from plant A for the period 1986-98. These files were converted to electronic form and consolidated into 3430 individual records, each with a full work history. Two North Island plants that processed sheep meat only provided similar records, with the final files containing 2057 individuals employed during the period 1981-96 at plant B, and 1196 individuals employed during 1987-98 at plant C. The three company subcohorts were combined into a single file; each individual record contained a full work history with the three companies, including employment with these companies that occurred in the period before commencement of follow up. The records of 36 individuals who had worked in more than one plant were consolidated to avoid counting workers and deaths more than once.

Study subjects were traced forward from their date of first employment (or 1 January 1988 if employment started before that date) until their date of death, cancer registration, emigration, or the last day of follow up (31 December 2000). Their mortality and cancer incidence was established by a combination of electronic and manual matching with national records for deaths and cancer registrations through the New Zealand Health Information Service (NZHIS). Those cohort members not registered as having died during the study period were followed to verify vital status by record linkage with both the 2001 New Zealand Electoral Roll (for which registration is compulsory) and with the client records of the Department of Work and Income (WINZ). In addition, record linkage with hospital discharge records held by the NZHIS was used to supplement the vital status information obtained from the main matches. For those cohort members who had died during the study period, the last date of follow up was the date of death. For all others the last date of follow up was the most recent date available from their work history, hospital discharge records, WINZ records, or the Electoral Roll.

For each cause of death or cancer type standardised mortality ratios (SMRs) and standardised incidence ratios (SIRs) were calculated as the ratio of observed to expected numbers of deaths and cancer registrations. Expected numbers were computed by multiplying the person-years, stratified by gender, age in five year bands and calendar year

\section{Policy implications}

- This occupational cause of cancer may be significant in public health terms given the number of workers employed in this industry worldwide.

- Further study is warranted to identify the specific agents responsible, in order that preventive measures can be developed.

in single years, by the New Zealand national rates using the NIOSH PC LTAS programme. ${ }^{36}$ Mortality and incidence rates for the period 1988-2000 were derived from the WHO Mortality Database. ${ }^{37}$ Ninety five per cent confidence intervals for the SMRs and SIRs were calculated under the assumption that the observed numbers of deaths or registrations followed a Poisson distribution. ${ }^{38}$

Each job title was assigned both a nominal and ordinal ranking with respect to potential for (and likely magnitude of) exposure to live animals, animal pelts or hides, the slaughter process or freshly slaughtered meat, animal urine, gastrointestinal microflora through animal faeces or gut contents, blood borne infectious agents, or specific process chemicals. Stratified analyses were conducted separately for selected causes in subgroups of workers defined according to exposure. The first such analyses examined all cause mortality, and mortality from all cancer, lung cancer, and cancers of lymphohaematopoietic tissue including nonHodgkin's lymphoma and leukaemia, by age at risk, duration of employment, and time since first employed. Internal comparisons were also made based on department "ever worked" in, and on job titles grouped into potential biological and chemical exposure categories. A further series of analyses examined mortality and cancer incidence by duration of employment in years in selected departments or in jobs that entailed specific biological or chemical exposures, and included a test for trend. ${ }^{39}$ As the numbers of cases were too small to give stable estimates of risk by level of exposure to individual biological agents, an analysis using exposure to any biological agents (animal urine, faeces, and blood) was conducted for overall cancer and for cancers of the lung, lymphohaematopoietic system, non-Hodgkin's lymphoma, and leukaemia.

\section{RESULTS}

The cohort comprised 6647 individuals assembled from plant A (3430), plant B (2057), and plant C (1196). Exclusions from the analysis $(\mathrm{n}=221)$ were made primarily where individuals had a last known date of follow up that was prior to the start of follow up at 1 January 1988. A description of each subcohort stratified according to factors such as duration of employment, age at risk, time since first employed, calendar period, and length of follow up, as well as the results of the follow up and vital status ascertainment, is presented in table 1. Follow up of the cohort involved 63160 person-years, the average length of follow up was 9.8 years, and $18 \%$ of the cohort was female. Vital status was determined for $84 \%$ of the cohort and $92 \%$ of the total possible person-years.

The majority of cohort members had been employed on the slaughterboard (44\% of person-years) or in meat cutting (25\%), with a further $10 \%$ employed in departments associated with the processing of edible and inedible offal and meat wastes. The largest remaining category (14\%) was those employed in plant services, which included maintenance workers, cleaners, and a floating labour pool. Relatively few had worked in jobs with live animal contact 


\begin{tabular}{|c|c|c|c|c|}
\hline & $\begin{array}{l}\text { Plant A } \\
\text { n (\%) }\end{array}$ & $\begin{array}{l}\text { Plant B } \\
\text { n (\%) }\end{array}$ & $\begin{array}{l}\text { Plant C } \\
\text { n (\%) }\end{array}$ & $\begin{array}{l}\text { Combined } \\
\text { n (\%) }\end{array}$ \\
\hline In database & 3430 & 2057 & 1196 & 6647 \\
\hline Exclusions & $36(1)$ & $147(7)$ & $38(3)$ & $221(3)$ \\
\hline Missing date of birth or gender & 32 & 41 & 38 & 111 \\
\hline Last date of follow up before 1 Jan 1988 & 4 & 103 & - & 107 \\
\hline Included in analysis. & 3394 (99) & $1910(93)$ & 1158 (97) & 6426 (97) \\
\hline \multicolumn{5}{|l|}{ Gender } \\
\hline Male & $2938(87)$ & $1415(74)$ & 918 (79) & $5239(82)$ \\
\hline Female & $456(13)$ & $495(26)$ & $240(21)$ & $1187(18)$ \\
\hline Total person-years of follow up & 33134 & 19933 & 10388 & 63160 \\
\hline Mean length of follow up (years) & 9.8 & 10.4 & 9.0 & 9.8 \\
\hline Mean duration of employment (years) & 8.9 & 4.7 & 5.9 & 7.1 \\
\hline Mean age at hire (years) & 29.1 & 30.0 & 33.0 & 30.1 \\
\hline \multicolumn{5}{|l|}{ Vital status at 31 Dec 2000} \\
\hline Alive & $2804(83)$ & $1546(81)$ & $811(70)$ & $5134(80)$ \\
\hline Deceased & $132(4)$ & $61(3)$ & $35(3)$ & $227(4)$ \\
\hline Lost to follow up & 458 (13) & $303(16)$ & $312(27)$ & 1065 (16) \\
\hline Total & 3394 & 1910 & 1158 & 6426 \\
\hline Person-years & 33134 & 19933 & 10388 & 63160 \\
\hline Total possible person-years & 35394 & 22649 & 11305 & 69014 \\
\hline Achieved follow up (as $\%$ of total possible person-years) & $94 \%$ & $88 \%$ & $92 \%$ & $92 \%$ \\
\hline
\end{tabular}

(4\%) or contact with animal pelts and hides $(8 \%)$. Although there was overlap in the biological exposure categories used, there were distinctions between those exposed to the slaughter process or raw meat $(75 \%)$, or to animal urine $(81 \%)$, faeces $(64 \%)$, or blood $(75 \%)$.

The findings for mortality, and for cancer incidence, are presented in tables 2 and 3 respectively. There was excess mortality from all causes (SMR 1.12, 95\% CI 0.98 to 1.27, 227 deaths) and all cancers (SMR 1.12, 95\% CI 0.88 to $1.42,69$ deaths), as well as from diseases of the circulatory system (SMR 1.15, 95\% CI 0.90 to $1.4,73$ deaths), respiratory system (SMR 1.10, 95\% CI 0.57 to $1.96,10$ deaths), digestive system (SMR 1.49, 95\% CI 0.62 to 3.07, 6 deaths), and from external causes (SMR 1.27, 95\% CI 0.96 to 1.65, 56 deaths). Among the cancers, significant excess mortality was observed for lung cancer (SMR 1.79, 95\% CI 1.13 to 2.68, 23 deaths).

Table 2 Total and cause specific mortality

\begin{tabular}{|c|c|c|c|c|c|}
\hline \multirow[b]{2}{*}{ Cause of death (ICD 9th revision) } & \multirow[b]{2}{*}{ Observed } & \multirow[b]{2}{*}{ Expected } & \multirow[b]{2}{*}{ SMR } & \multicolumn{2}{|c|}{$95 \% \mathrm{Cl}$} \\
\hline & & & & Lower & Upper \\
\hline All causes & 227 & 203.57 & 1.12 & 0.98 & 1.27 \\
\hline All malignant neoplasms (140-208) & 69 & 61.38 & 1.12 & 0.88 & 1.42 \\
\hline Oral cavity and pharynx (140-149) & 2 & 1.36 & 1.47 & 0.18 & 5.30 \\
\hline Oral cavity $(141-145)$ & 2 & 0.65 & 3.09 & 0.38 & 11.17 \\
\hline Oesophagus (150) & 3 & 1.76 & 1.70 & 0.35 & 4.98 \\
\hline Stomach (151) & 4 & 2.80 & 1.43 & 0.39 & 3.65 \\
\hline Colon (153) & 6 & 5.68 & 1.06 & 0.39 & 2.30 \\
\hline Rectum (154) & 1 & 3.71 & 0.27 & 0.01 & 1.50 \\
\hline Liver, specified as primary (1550) & 1 & 1.27 & 0.79 & 0.02 & 4.39 \\
\hline Gall bladder (156) & 1 & 0.36 & 2.81 & 0.07 & 15.59 \\
\hline Pancreas (157) & 2 & 2.29 & 0.87 & 0.11 & 3.16 \\
\hline Larynx (161) & 1 & 0.38 & 2.63 & 0.07 & 14.62 \\
\hline Lung (162) & 23 & 12.87 & 1.79 & 1.13 & 2.68 \\
\hline Melanoma (172) & 4 & 3.00 & 1.33 & 0.36 & 3.41 \\
\hline Breast (174-175) & 1 & 2.62 & 0.38 & 0.04 & 1.78 \\
\hline Female genital organs (179-184) & 1 & 1.21 & 0.83 & 0.02 & 4.61 \\
\hline Prostate (185) & 2 & 2.78 & 0.72 & 0.09 & 2.59 \\
\hline Bladder (188) & 2 & 0.88 & 2.28 & 0.28 & 8.23 \\
\hline Brain (191) & 2 & 2.97 & 0.67 & 0.08 & 2.43 \\
\hline Thyroid (193) & 2 & 0.13 & 15.55 & 1.88 & 56.15 \\
\hline III defined $(195,199)$ & 4 & 3.48 & 1.15 & 0.39 & 2.74 \\
\hline Lymphatic and haematopoietic tissue (200-208) & 6 & 6.26 & 0.96 & 0.35 & 2.09 \\
\hline Non-Hodgkin's lymphoma $(200,202)$ & 4 & 2.75 & 1.45 & 0.49 & 3.45 \\
\hline Leukaemia and aleukaemia (204-208) & 2 & 2.34 & 0.86 & 0.17 & 2.75 \\
\hline Benign neoplasms $(210-239)$ & 2 & 0.65 & 3.07 & 0.37 & 11.07 \\
\hline Dis. of endocrine system \& blood (240-289) & 4 & 9.16 & 0.44 & 0.15 & 1.04 \\
\hline Mental disorders $(290-319)$ & 1 & 2.13 & 0.47 & 0.01 & 2.61 \\
\hline Dis. of nervous system (320-359) & 3 & 4.21 & 0.71 & 0.15 & 2.09 \\
\hline Dis. of circulatory system (390-459) & 73 & 63.73 & 1.15 & 0.90 & 1.44 \\
\hline Dis. of respiratory system $(460-519)$ & 10 & 9.06 & 1.10 & 0.57 & 1.96 \\
\hline Dis. of digestive system (520-579) & 6 & 4.02 & 1.49 & 0.62 & 3.07 \\
\hline Dis. of urinary system $(580-599)$ & 1 & 1.28 & 0.78 & 0.02 & 4.34 \\
\hline Dis. of skin $(680-739)$ & 1 & 0.75 & 1.34 & 0.12 & 6.23 \\
\hline Symptoms and ill defined conditions (780-799) & 1 & 0.42 & 2.37 & 0.06 & 13.18 \\
\hline External causes (e800-999) & 56 & 44.20 & 1.27 & 0.96 & 1.65 \\
\hline
\end{tabular}




\begin{tabular}{|c|c|c|c|c|c|}
\hline \multirow[b]{2}{*}{ Site (ICD 9th revision) } & \multirow[b]{2}{*}{ Observed } & \multirow[b]{2}{*}{ Expected } & \multirow[b]{2}{*}{ SIR } & \multicolumn{2}{|c|}{$95 \% \mathrm{Cl}$} \\
\hline & & & & Lower & Upper \\
\hline All malignant neoplasms (140-208) & 143 & 150.34 & 0.95 & 0.80 & 1.12 \\
\hline Oral cavity and pharynx (140-149) & 5 & 4.45 & 1.12 & 0.36 & 2.62 \\
\hline Oesophagus (150) & 3 & 1.94 & 1.55 & 0.32 & 4.53 \\
\hline Stomach (151) & 5 & 3.77 & 1.33 & 0.43 & 3.10 \\
\hline Colon (153) & 16 & 12.90 & 1.24 & 0.71 & 2.01 \\
\hline Rectum (154) & 6 & 8.63 & 0.70 & 0.25 & 1.51 \\
\hline Liver, specified as primary (1550) & 1 & 1.89 & 0.53 & 0.01 & 2.94 \\
\hline Gall bladder (156) & 1 & 0.54 & 1.86 & 0.05 & 10.31 \\
\hline Pancreas (157) & 2 & 2.48 & 0.81 & 0.10 & 2.91 \\
\hline Larynx (161) & 4 & 1.36 & 2.95 & 0.80 & 7.55 \\
\hline Lung (162) & 26 & 15.29 & 1.70 & 1.11 & 2.49 \\
\hline Bone (170) & 1 & 0.74 & 1.36 & 0.03 & 7.55 \\
\hline Soft tissue (171) & 2 & 2.68 & 0.75 & 0.09 & 2.70 \\
\hline Melanoma (172) & 12 & 21.82 & 0.55 & 0.28 & 0.96 \\
\hline Breast (174-175) & 5 & 9.49 & 0.53 & 0.17 & 1.23 \\
\hline Female genital organs (179-184) & 7 & 4.15 & 1.69 & 0.68 & 3.47 \\
\hline Prostate (185) & 9 & 16.92 & 0.53 & 0.24 & 1.01 \\
\hline Testis (186) & 11 & 5.69 & 1.93 & 0.96 & 3.46 \\
\hline Bladder (188) & 3 & 4.92 & 0.61 & 0.13 & 1.78 \\
\hline Kidney (189) & 3 & 3.96 & 0.76 & 0.16 & 2.22 \\
\hline Brain (191) & 1 & 3.80 & 0.26 & 0.01 & 1.46 \\
\hline Thyroid (193) & 3 & 1.63 & 1.84 & 0.38 & 5.38 \\
\hline III defined $(195,199)$ & 5 & 4.81 & 1.04 & 0.34 & 2.43 \\
\hline Lymphatic and haematopoietic tissue (200-208) & 11 & 13.56 & 0.81 & 0.41 & 1.45 \\
\hline Non-Hodgkin's lymphoma $(200,202)$ & 6 & 6.07 & 0.99 & 0.36 & 2.15 \\
\hline Hodgkin's disease (201) & 1 & 1.31 & 0.76 & 0.02 & 4.24 \\
\hline Leukaemia and aleukaemia (204-208) & 4 & 4.53 & 0.88 & 0.30 & 2.10 \\
\hline
\end{tabular}

Overall cancer incidence was close to expected (SIR 0.95, 95\% CI 0.80 to $1.12,143$ cases), although there was a significant excess of lung cancer (SIR 1.70, 95\% CI 1.11 to 2.49, 26 cases). The incidence of cancers of the lymphatic and haematopoietic system was lower than expected (SIR 0.81, $95 \%$ CI 0.41 to $1.45,11$ cases).

The relation between duration of employment in selected departments or jobs that entail potential exposure to selected biological agents and the incidence of cancers of the lung and the lymphohaematopoietic system, are shown in tables 4 and 5 respectively. Significant trends were evident for increasing risk of lung cancer with increasing duration of employment in job titles with potential exposure to animal faeces and blood, with a threefold excess observed in those with more than 15 years employment. Significant trends of increasing risk of lymphohaematopoietic cancer with increasing duration of employment were also observed in the processing or plant services departments, or in job titles with potential exposure to animal urine and faeces.

In an analysis of the incidence of selected cancers by level of exposure to any biological material (contained in animal urine, faeces or blood) a trend was apparent for lung cancer, with no excess in those with no exposure (SIR 1.05, 95\% CI 0.29 to $2.80,3$ cases), increased risk in those with medium exposure (SIR 1.53, 95\% CI 0.58 to 3.35, 5 cases), and significantly $(\mathrm{p}<0.01)$ increased risk in those with high exposure (SIR 1.97, 95\% CI 1.21 to $3.04,18$ cases).

\section{DISCUSSION}

This historical cohort study was undertaken to examine mortality and cancer incidence in a group of workers employed in the New Zealand meat processing industry, and also to investigate associations between specific exposures and any increased cancer risk identified. As in any observational epidemiological study of this type there are a number of potential sources of bias, including incompleteness of follow up, uncontrolled confounding by ethnicity or lifestyle factors such as smoking, and misclassification of exposure.
Incompleteness of follow up is a potential source of selection bias only where the degree of incompleteness differs in the groups being compared. Ascertainment of vital status in this study was by the same method for all cohort members, and was therefore unlikely to introduce significant bias. The rate of follow up achieved is comparable to that in recent New Zealand occupational cohort studies, which ranged from $90 \%{ }^{40}$ to $95 \%$ of the possible person-years. ${ }^{41}$

While there is no information on ethnicity in this cohort, it would be reasonable to assume a high proportion of Maori (the indigenous people of New Zealand) in the study population compared to that in the general population. In a recent study of meat workers from the same area as plants $\mathrm{B}$ and C, approximately 50\% of workers employed during the period 1986 to 1994 were Maori. ${ }^{42}$ Given the South Island location of plant A it is likely to have a lower proportion of Maori workers, so it would be reasonable to assume that 35$40 \%$ of the entire cohort (or just over twice the proportion in the general population) were Maori. Mortality from lung cancer among adult Maori males in the period 1987-91 was 1.4 times that of non-Maori New Zealanders, while for adult Maori females it was 2.8 times. ${ }^{43}$ Using the assumption that this cohort (20\% female) was $40 \%$ Maori, compared with approximately $15 \%$ in the general population, the relative risk of lung cancer attributable to ethnicity can be calculated to be 1.09 .

A related source of potential uncontrolled confounding in this study is the lack of information on smoking among cohort members. This is particularly relevant to the findings related to lung cancer, although the effect of confounding by smoking in studies of occupational cancer is often relatively weak, as differences in smoking rates between groups of manual workers are fairly small. ${ }^{44}$ For example, $65.4 \%$ of New Zealand food and beverage workers had ever smoked compared with $59.6 \%$ of the total full time labour force (and $46.8 \%$ current smokers versus $37.7 \%$ respectively) in 1981 census data. ${ }^{18}$ Even where comparisons are made with national mortality rates, the most extreme differences in smoking status are unlikely to account for a relative risk of 

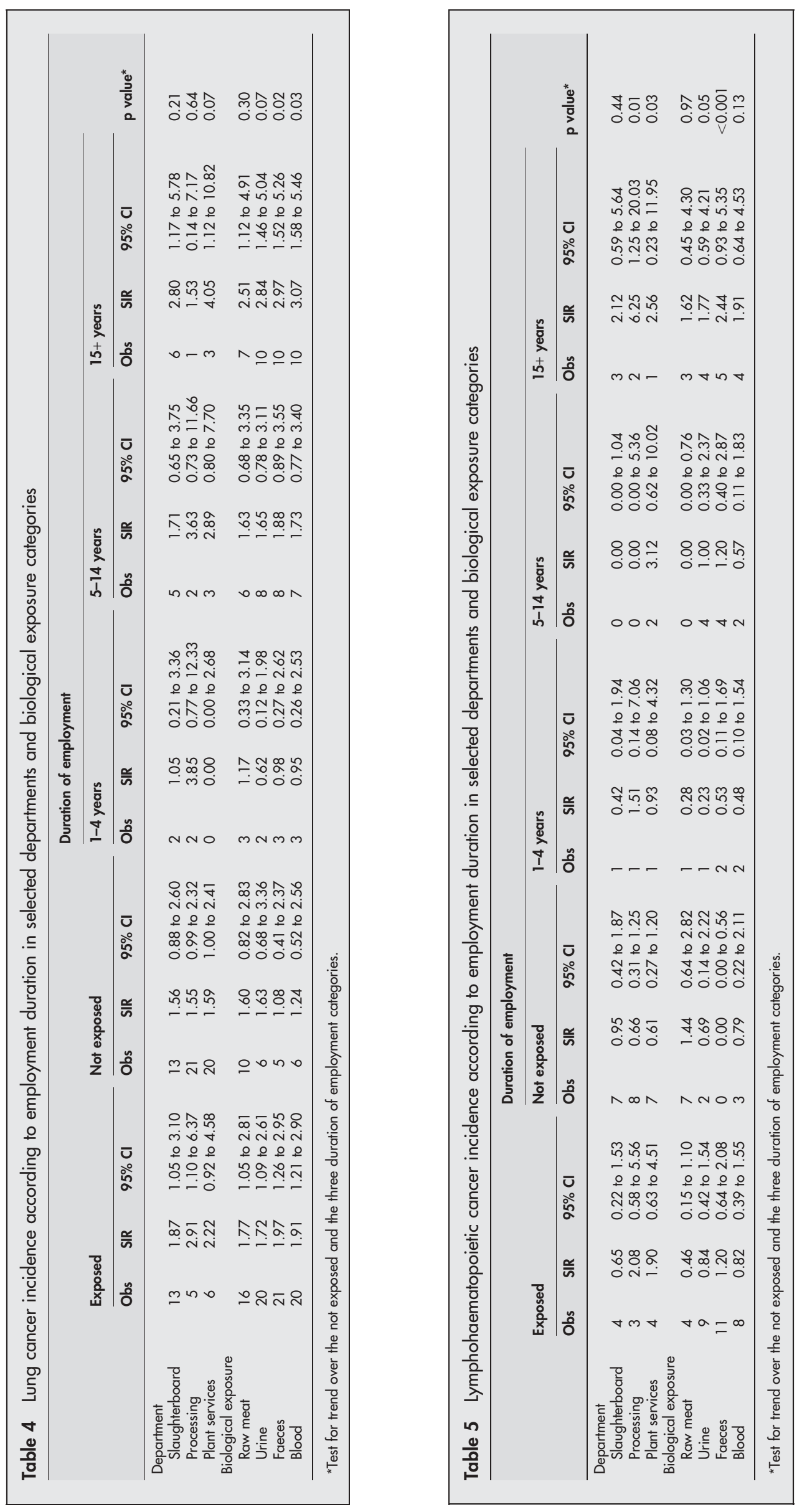

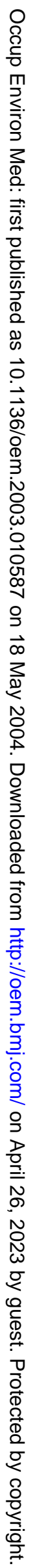


greater than $1.5 .^{38}$ In the earlier New Zealand study the odds ratio for lung cancer attributable to the higher smoking rates among meat workers was estimated using the method of Axelson ${ }^{45}$ to be $1.20 .^{18}$ Thus, the high smoking rates in this cohort would only account for a relative risk of lung cancer of about 1.2, while the high proportion of Maori would only account for a relative risk of about 1.1. These cannot be simply multiplied together because each "bias" partly depends on the other as Maori have higher rates of smoking, ${ }^{43}$ but these estimates do show that the total confounding effect of smoking and ethnicity on lung cancer relative risk in the company cohort is likely to be less than 1.25 .

Cancers of the oral cavity, oesophagus, larynx, bladder, pancreas, and kidney are also recognised as being related to smoking, ${ }^{46}$ and would be increased in a cohort with higher rates of smoking. While a summary estimate of mortality from these cancers in this cohort (SMR 1.31, 10 deaths) suggests a contribution to the excess lung cancer from smoking (and/or ethnicity), it should be noted that laryngeal cancer has also been found in other studies to be associated with exposures in this industry ${ }^{30}{ }^{31}$ and also to have been increased above levels that could be attributed to smoking. ${ }^{18} 47$

The use of job titles to characterise exposure has limitations as it may reflect dose in only a limited way, and misclassification of exposure is inevitable when using job title as a surrogate of exposure. This misclassification is nondifferential, however, so its effect would be to dilute any true association between the exposure and the outcome and consequently lead to an underestimation of the strength of that association. ${ }^{38}$ While the primary categorisation of exposure in this study was based on workers' departments and job titles, grouping these into categories based on potential for exposure to the range of biological and chemical agents represents a more detailed exposure assessment than has been reported for previous meat worker cohorts. Exposure categorisation in these earlier studies has been based on very broad categories such as exposure to live animals, warm meat, chilled meat, or bacon process and products, ${ }^{28}$ to ever having worked in abattoirs, meatpacking plants, meat department of supermarkets, chicken slaughtering plants, and non-meat companies, ${ }^{8-10} 2627$ or in the large Swedish cohort to having been classified as butchers or meat workers in one or more consecutive censuses. ${ }^{31}$ This study combines a more detailed exposure assessment with a cohort of sufficient size for examination of all but the most rare cancers. It was not possible, however, to isolate the effects of the different exposures (for example, blood and urine) because of significant overlap and/or relatively small numbers in certain categories.

The prevalence and magnitude of exposure to certain agents, both biological and chemical, will have changed over time in the New Zealand industry. For example, exposure to brucellosis infection would have increased dramatically in meat workers engaged in the slaughter of infected cattle with the introduction of an eradication programme in 1969, would have continued at an increased rate until the early 1980s while reactor cattle were being selectively culled for slaughter, then would have been eradicated entirely by the end of the 1980s (Glass, personal communication). More recently, a similar programme of selective culling of BLV infected cattle, which began in 1997, would have increased the potential for exposure of meat workers engaged in the slaughter of cattle to this known animal oncogenic retrovirus. ${ }^{48}$ The period of observation in this study did not permit examination of possible trends associated with these changes. It is possible, however, that the increasing relative risk observed with increasing duration of exposure could be related to either the latency period between disease induction and manifestation, or to an effect related to an exposure that occurred in the past but which is now reduced or eliminated.

Notwithstanding the limitations of this study, associated with the potential for misclassification of exposure and uncontrolled confounding by ethnicity and smoking, there are two key findings that are of considerable interest. The first is that there is an excess of lung cancer, for which there is a strong dose-response relation based on duration of exposure in certain departments and which is most strongly associated with exposures to biological material in animal urine, faeces, or blood. The second finding is that despite small numbers there is evidence of a dose-response relation between both mortality from, and incidence of, cancers of the lymphohaematopoietic system with increasing duration of work in meat processing and plant services, and particularly with increasing exposure to animal faeces. This effect appears to exist for non-Hodgkin's lymphoma, and possibly also for leukaemia.

These findings for lung cancer are consistent with findings for meat workers from previous cohort studies, although the overall lung cancer SMR of 1.79 is higher than all the studies except for the SMR of 2.1 reported for non-white males in abattoirs $^{10}$ and 2.5 for the Danish slaughterhouse cohort. ${ }^{2}$ The level of risk observed in the internal analyses in this studythat is, a more than threefold increase for specific departments or exposures with the longest duration, is also higher than any reported previously. The exposures found to be most closely associated with excess lung cancer risk in this study are also similar to those identified previously, although this study indicates that the strongest associations are with biological material from animal urine, faeces, and blood rather than the association with the slaughter process and contact with raw meat implicated in previous studies. The findings for lymphohaematopoietic cancers in this study are not strong, and are similar to the findings of earlier cohort studies.

Case-control studies have found highly variable relative risks for lung cancer, with most being lower than the levels observed in this study. The one study that examined the effect of dose, however, reported a relative risk of 13.1 in those with contact with raw meat in abattoirs for a period in excess of five years. ${ }^{19}$ Although there is the potential for information bias in a case-control study, it is equally possible that an effect of similar magnitude in a cohort study could have been attenuated by non-differential exposure misclassification. In contrast to the findings for lung cancer, although several case-control studies (including a series conducted in New Zealand) have observed significant excesses in risk of lymphohaematopoietic cancers, few cohort studies have observed any excess. This study did not find the excess risk of lymphohaematopoietic cancers observed in previous New Zealand case-control studies, although the association observed between increasing dose and increasing risk suggests that the effect may be real.

In conclusion, therefore, this study has shown a significant excess of lung cancer. It is not possible to completely rule out the possibility of confounding by smoking and/or ethnicity, but it is highly unlikely that either is sufficient to account for more than a small part of the excess observed. The strong dose-response relation observed also supports the hypothesis that the effect is related to occupational exposures, and in particular to some component of the biological material contained in animal urine, faeces, and blood. The study has also provided some support for the previous findings of excess risks of leukaemia and non-Hodgkin's lymphoma associated with work in the New Zealand meat industry, due primarily to the association observed between increasing risk and increasing duration of exposure to the same biological material. 


\section{ACKNOWLEDGEMENTS}

This study was funded by a project grant (HRC 00/281) from the Health Research Council of New Zealand. During the conduct of the research, Dave McLean was supported by a Public Health Research Training Fellowship, the Centre for Public Health Research was supported by a Programme Grant, both from the Health Research Council of New Zealand, and Andrea 't Mannetje was supported by a Special Training Award at the International Agency for Research on Cancer.

\section{Authors' affiliations}

D McLean, S Cheng, A 't Mannetie, N Pearce, Centre for Public Health Research, Research School of Public Health, Massey University, Wellington Campus, New Zealand

A Woodward, Department of Public Health, Wellington School of Medicine, University of Otago, Wellington, New Zealand

\section{REFERENCES}

1 Lynge E, Andersen O, Kristensen TS. Lung cancer in Danish butchers. Lancet 1982;1:527-8.

2 Fox AJ, Lynge E, Malker H. Lung cancer in butchers. Lancet 1982;1:165-6.

3 Griffith GW. Lung cancer in butchers. Lancet 1982;1:399.

4 Lagorio S, Forastiere F, Rapiti E, et al. Attivita economiche e professioni ad elevato rischio di mortalita per fumore polomonare a Torino (1981-89) e in Italia (1981-82). Med Lav 1995;86:309-24.

5 Morton W, Marjanovich D. Leukemia incidence by occupation in the PortlandVancouver metropolitan area. Am J Ind Med 1984;6:185-205.

6 Milham S. Lung cancer in butchers. Lancet 1982;1:690.

7 Johnson ES, Fischman HR. Cancer mortality among butchers and slaughterhouse workers. Lancet 1982;1:913-14.

8 Johnson ES, Fischman HR, Matanoski GM, et al. Cancer mortality among white males in the meat industry. J Occup Med 1986a;28:23-32.

9 Johnson ES, Fischman HR, Matanoski GM, et al. Occurrence of cancer in women in the meat industry. Br J Ind Med 1986;43:597-604

10 Johnson ES. Mortality among non-white men in the meat industry. J Occup Med 1989;31:270-2.

11 Vena JE, Byers T, Swanson M, et al. Lung cancer in butchers. Lancet 1982;2:713.

12 Gustavsson P, Fellenius E, Hogstedt C. Possible causes of increased lung cancer incidence among butchers and slaughterhouse workers. Scand J Work Environ Health 1987; 13:518-23.

13 Pearce NE, Smith AH, Fisher DO. Malignant lymphoma and multiple myeloma linked with agricultural occupations in a New Zealand cancer registry-based study. Am J Epidemiol 1985;121:225-37.

14 Pearce NE, Smith AH, Howard JK, et al. Non-Hodgkin's lymphoma and exposure to phenoxyherbicides, chlorophenols, fencing work, and meat works employment: a case-control study. Br J Ind Med 1986;43:75-83.

15 Pearce NE, Sheppard RA, Howard JK, et al. Leukaemia among New Zealand agricultural workers. A cancer registry-based study. Am J Epidemiol 1986; 124:402-9.

16 Pearce NE, Sheppard RA, Smith AH, et al. Non-Hodgkin's lymphoma and farming: an expanded case-control study. Int J Cancer 1987;39:155-61.

17 Pearce N, Smith AH, Reif JS. Increased risks of soft tissue sarcoma, malignan lymphoma, and acute myeloid leukemia in abattoir workers. Am J Ind Med 1988; 14:63-72.

18 Reif JS, Pearce NE, Fraser J. Cancer risks among New Zealand meat workers. Scand J Work Environ Health 1989;15:24-9.

19 Johnson ES. Nested case-control study of lung cancer in the meat industry. J Natl Cancer Inst 1991;83:1337-9.

20 Loomis DP, Savitz DA. Occupation and leukemia mortality among men in 16 states: 1985-1987. Am J Ind Med 1991;19:509-21.
21 Tatham L, Tolbert P, Kjeldsberg C. Occupational risk factors for subgroups of non-Hodgkin's lymphoma. Epidemiology 1997;8:551-8.

22 Jockel KH, Ahrens W, Jahn I, et al. Occupational risk factors for lung cancer: a case-control study in West Germany. Int J Epidemiol 1998;27:549-60.

23 Metayer C, Johnson ES, Rice JC. Nested case-control study of tumors of the hemopoietic and lymphatic systems among workers in the meat industry. Am J Epidemiol 1998; 147:727-38.

24 Bethwaite P, McLean D, Kennedy J, et al. Adult-onset leukaemia and employment in the meat industry: a New Zealand case-control study. Cancer Causes Control 2001;12:635-43.

25 Bouchardy C, Schuler G, Minder C, et al. Cancer risk by occupation and socioeconomic group among men-a study by The Association of Swiss Cancer Registries. Scand J Work Environ Health 2002;28(suppl 1):1-88.

26 Johnson ES. Cancer mortality among workers in the meat department of supermarkets. Occup Environ Med 1994;51:541-7.

27 Johnson ES, Dalmas D, Noss J, et al. Cancer mortality among workers in abattoirs and meatpacking plants: an update. Am J Ind Med 1995;27:389-403

28 Coggon D, Pannett B, Pippard EC, et al. Lung cancer in the meat industry. $\mathrm{BrJ}$ Ind Med 1989;46:188-91.

29 Coggon D, Wield G. Mortality of butchers and cooks identified from the 1961 census of England and Wales. Occup Environ Med 1995:52:157-9.

30 Guberan E, Usel M, Raymond L, et al. Mortality and incidence of cancer among a cohort of self employed butchers from Geneva and their wives. $\mathrm{Br} J$ Ind Med 1995;50:1008-016.

31 Boffetta P, Gridley G, Gustavsson P, et al. Employment as butcher and cancer risk in a record-linkage study from Sweden. Cancer Causes Control 2002; 11:627-33.

32 Pearce N, Reif JS. Epidemiologic studies of cancer in agricultural workers. Am J Ind Med 1990;18:133-48.

33 Kristensen TS, Lynge $E$. Lung cancer among butchers and slaughterhouse workers. Scand J Work Environ Health 1993;19:137-47.

34 New Zealand Health Information Service. Cancer: new registrations and deaths 1999. Wellington: Ministry of Health, 2002.

35 Brown SH, Frankovich M. "How accurate are New Zealand death certificates?". N Z Med J 1998;111:321-2.

36 Steenland K, Spaeth S, Cassinelli R, et al. NIOSH Life Table Programme for Personal Computers. Am J Ind Med 1998;34:517-18.

37 World Health Organisation (WHO). WHO Mortality Data Base (MDB), WHO Statistical Information System (WHOSIS). http://www.who.int/whosis/mort/ download.htm. Geneva: World Health Organisation, 2001.

38 Checkoway H, Pearce NE, Crawford-Brown DJ. Research methods in occupational epidemiology. New York: Oxford University Press, 1989.

39 Pearce N, Cryer PC. Analysis of the components of a linear trend in proportions. Am J Epidemiol 1986;124:127-3.

40 Firth HM, Elwood JM, Cox B, et al. Historical cohort study of a New Zealand foundry and heavy engineering plant. Occup Environ Med 1999;56:134-8.

41 Fawcett J, Garrett N, Bates MN. Follow-up methods for retrospective cohort studies in New Zealand. Aust N Z J Public Health 2002;26:256-61.

42 Keefe V, Reid P, Ormsby C, et al. Serious health events following involuntary job loss in New Zealand meat processing workers. Int J Epidemiol 2002;31:1155-61.

43 Pomare E, Keefe-Ormsby V, Ormsby C, et al. Hauora Maori Standards of Health III, A study of the years 1970-1991. Te Ropu Rangahau Havora a Eru Pomare. Wellington: School of Medicine, 2002.

44 Siemiatycki J, Wacholder S, Dewar R, et al. Smoking and degree of occupational exposure: are internal analyses in cohort studies likely to be confounded by smoking status? Am J Ind Med 1988;13:59-69.

45 Axelson O. Aspects on confounding in occupational health epidemiology. Scand J Work Environ Health 1978;4:98-102.

46 Stewart BW, Kleihues P, eds. World cancer report. Lyon: IARC Press, 2003

47 De Stefani E, Boffetta P, Oreggia F, et al. Occupation and the risk of laryngeal cancer in Uruguay. Am J Ind Med 1998:33:537-42.

48 Hayes D. Enzootic bovine leucosis eradication scheme. Surveillance 2002;29:25 